\title{
Taking programs for vulnerable adolescents to scale: Experiences, insights, and evidence
}

Martha Brady

Population Council

Follow this and additional works at: https://knowledgecommons.popcouncil.org/departments_sbsr-pgy

Part of the Demography, Population, and Ecology Commons, Family, Life Course, and Society Commons, Gender and Sexuality Commons, Inequality and Stratification Commons, International Public Health Commons, and the Medicine and Health Commons How does access to this work benefit you? Let us know!

\section{Recommended Citation}

Brady, Martha. 2011. "Taking programs for vulnerable adolescents to scale: Experiences, insights, and evidence," Promoting Healthy, Safe, and Productive Transitions to Adulthood Brief no. 36. New York: Population Council. 


\title{
Taking programs for vulnerable adolescents to scale: Experiences, insights, and evidence
}

\author{
Prepared by Martha Brady
}

$\mathrm{T}$ he international development community's desire to alleviate poverty and improve health outcomes presents an extraordinary opportunity to transform the lives of young people, particularly girls. Cycles of illiteracy, poor job prospects, and social isolation can be broken, but will require concerted efforts to reach large numbers of vulnerable adolescent girls with robust asset-building programs. Scaling-up effective pilot programs will be critical to achieving these goals. While there is an expanding body of research around scaling-up health interventions, less is known or documented about scaling-up cross-sectoral programs for adolescent girls. Bringing to scale programs directed toward poor, often invisible and voiceless girls, poses unique challenges. Given that this is a relatively new field at an early stage of experimentation, the evidence base regarding which strategies are most effective is still emerging. The Population Council has been exploring a variety of approaches to meet these challenges in diverse settings and gathering evidence to inform program and policy development.

Varying definitions and approaches to scale-up

Scaling-up is a topic of frequent discussion, but relatively little rigorous study. Although the term "scaling-up" is now widely used in the health and development literature, it lacks formal definition. There is no consensus as to terminology or framework for studying scaling-up in the context of international health and development (DeJong 2002; Simmons, Fajians, and Ghiron 2007). "Scaling-up" has been used interchangeably with "going to scale" and "at scale," and may encompass both inputs and outputs. Typically these terms have been used to describe an increase in coverage and geographic reach of a particular intervention. In the health arena, "scaling-up" is generally associated with specific outcomes, such as increased access to or demand for health services and supplies (Mangham and Hanson 2010). While important, a

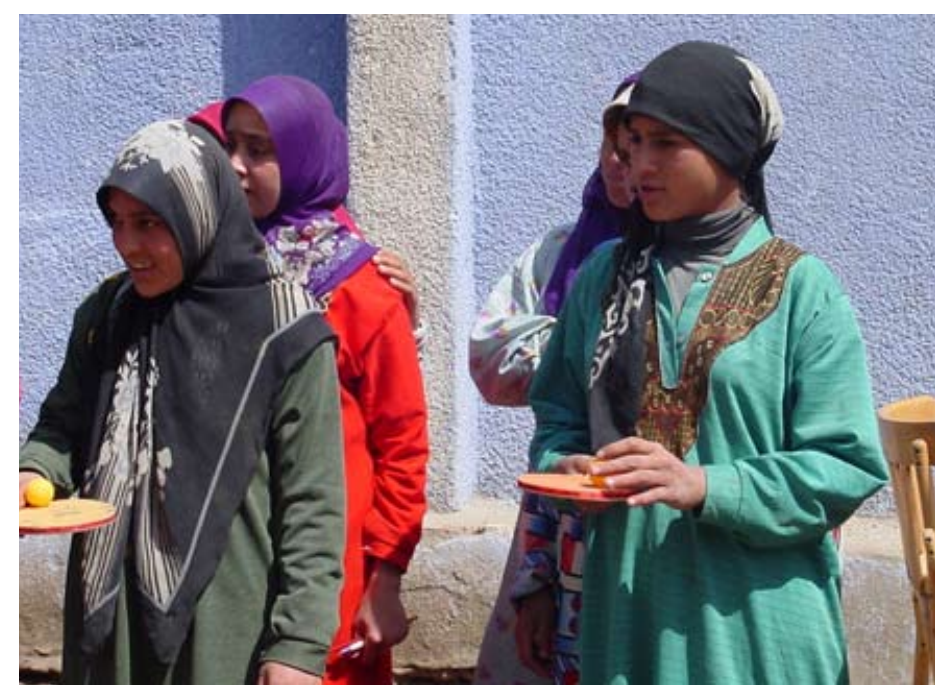

Scaling-up programs for adolescent girls requires the engagement of multiple sectors and diverse gatekeepers.

goal of increasing coverage alone is not sufficient to address the many challenges facing adolescent girls. Attention to content and quality, as well as the process of institutionalization, is essential.

\section{Scaling-up as institutionalization process}

Scaling-up might also be viewed as an organizational, managerial, political, and policy task that requires strategic planning and management (Simmons et al 2007). It is a process of institutionalization that engages multiple actors, interest groups, and organizations. Given that most adolescent girls programs are multi-sectoral, identifying the appropriate institution(s) to adopt the innovation is a key step along the critical path to scale-up. Scaling-up is also a dynamic process. At certain stages, the aim may be to increase coverage, while at others it 
may be to increase efficiency of an initiative or program that is already operating at a large scale. Very often, scaling-up is uneven in terms of pace, equity, and reach. At various times there may be tension among different dimensions of scale, quality, coverage, and impact (DeJong 2003). Appreciation of divergent stakeholder views is important in designing a scale-up strategy.

Key observations around scaling-up adolescent girls programs Population Council researchers are working in a number of settings to bring multi-sectoral adolescent girls programs to scale. In Bangladesh, Egypt, Ethiopia, Guatemala, and South Africa, the Council is working with program partners of varying size and capacity, at different stages of scaling-up, and in diverse socio-political environments. Even though the program content and populations of adolescent girls are diverse (e.g. rural, married girls in Ethiopia, urban girls in South Africa, indigenous girls in Guatemala, rural girls at risk of marriage in Bangladesh, and out-of- school girls in Upper Egypt), the interventions share core principles: creating safe spaces, engaging/involving girls' gatekeepers, providing girls with female mentors, and offering a multi-sectoral assetbuilding approach.

\section{Challenges of scaling-up programs for vulnerable girls}

While the need to scale-up effective interventions is great, the challenges of doing so are considerable. Often the institutional and management capacity to take a program to scale is not in place; funds for scale-up can rarely be found in country budgets. And while time is required for scaling-up, pace is also critical to maintain the interest of policymakers and donors. The temporal aspect is particularly salient since many of the outcomes being sought are long-term. In addition, a number of underlying issues make scaling-up adolescent girls programs uniquely challenging. For example, unlike in other areas where "demand" is clear and calculable, typically girls are not in a position to articulate demand in a way that is heard by policymakers. Many girls are effectively outside of the public sphere and have limited access to institutions and community resources. Thus "access" to any given intervention requires working through girls' gatekeepers.

One of the most critical issues is identifying an appropriate institutional home for the innovation. Because the programs are multi-sectoral with components related to education, health, livelihoods, and sports, they do not lend themselves readily to a singular "owner," such as a government ministry. The Council is working with partners across the spectrum from small local NGOs to large-scale international NGOs and government entities (local and national). In the case of Bangladesh, scaling-up is within the context of large NGO programs, while in Ethiopia the program is broadening its reach through government. In both Egypt and Guatemala, a hybrid model engaging both the public and private sectors is being pursued. In South Africa, the program is poised to scale-up within the context of the government education system.
Transfer of the innovation from originator to adopter; roles of NGO and government

Scaling-up involves transferring the model from one set of actors (the originators) to another, the "adopters." This can take several forms. While NGOs are often viewed as social innovators, having more agility and ability to do novel work, there may be a presumption that ultimately it is the role of the public sector to take an innovation to scale. At the same time, it is widely recognized that many government public systems (e.g. education, health) are weak. Scaling-up an NGO program may entail organizational expansion or establishing branches in other geographic areas, or engaging in partnerships with other NGOs or governmental bodies. In some cases NGOs train or fund other NGOs to undertake work in a specialized field, while in other cases they have recognized that the most effective way to reach a greater scale is to capitalize on the national reach and accountability of governments. Government entities are typically motivated by a desire to reach a significant proportion, or even all, of a given population for reasons of equity, as well as politics; cost and sustainability are critical concerns for government.

\section{Maintaining quality and fidelity while containing costs}

Moving from pilot to scale requires attention to content, structure, and cost. Unless carefully planned from the outset, pilots are often intensive and costly, reducing the likelihood of being adopted. Thus it important to identify the essential elements to achieve the desired outcome. Streamlining content and delivery is critical for cost containment, feasibility, and sustainability.

\section{Conditions that enhance the likelihood of successful scale-up}

The diffusion-of-innovation literature (Rogers 1995) provides useful insights about the attributes or conditions that predict successful scaleup. For example, there is a greater likelihood of success if the model or innovation is:

- Credible (based on sound evidence of benefit) - "proof of concept"

- Observable; intended beneficiaries (and other stakeholders) can see results

- Relevant (addressing a present or sharply felt problem)

- Offers a relative advantage over existing practices or models

- Easy to "install" or transfer to implementing entities

- Flexible; integrates new evidence and learning

- Testable

\section{Abriendo Oportunidades-"Creating Opportunities"}

The Abriendo Oportunidades program, implemented by the Population Council and local cross-sector partners in Guatemala's rural indigenous communities, has moved from a pilot project to an increasingly scaled program with plans for national institutionalization. The program, which creates safe spaces and leadership opportunities for Mayan girls ages $8-18$, began as a local NGO effort in a dozen villages, and has now 


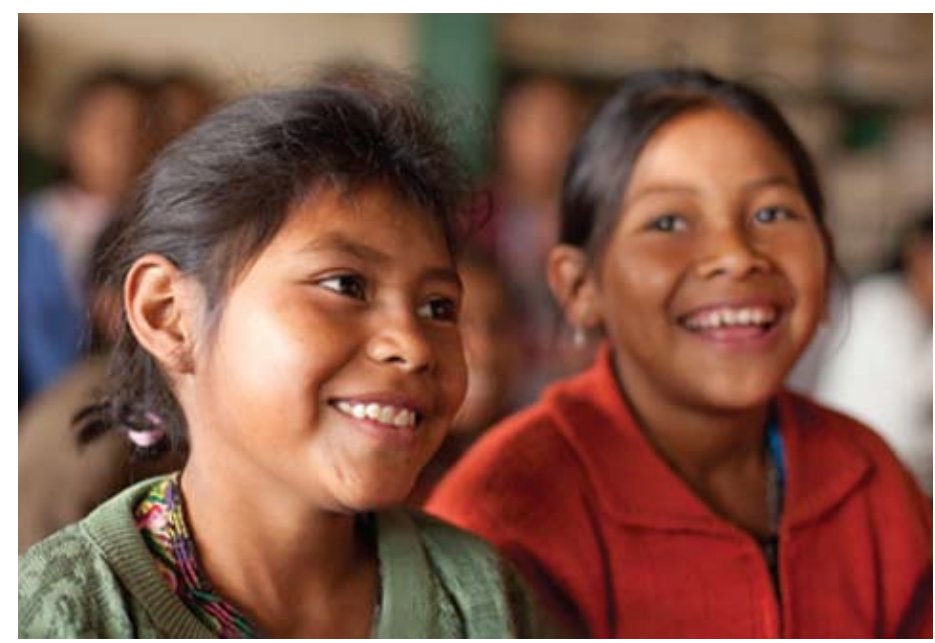

More than just numbers! Scaling-up programs for adolescent girls is a strategic process of institutionalization and the solidification of rights into various structures.

reached more than 3,000 girls in 40 indigenous communities. Abriendo is expanding at an average of ten new communities per year. Local governments, as well as NGOs and the private commercial sector, are increasingly engaged, providing the necessary anchors for sustainability and institutionalization. In addition to the expansion of the program itself, the Abriendo Oportunidades model is being adopted and replicated by public, NGO, and private-sector partners in Guatemala, and is poised to become the first national program for indigenous girls in the region.

\section{Ishraq-"Sunrise"}

In rural Upper Egypt, where girls are three times less likely than girls in urban areas to be enrolled in school, the Population Council and its partners designed a program aimed at bringing marginalized rural girls into safe learning spaces to improve their education, health, and social opportunities. The Ishraq program emphasizes literacy and life skills, health and hygiene education, civic engagement, and a first-ever governorate-level girls' sports program. Building on the success of the pilot in four villages with a few hundred girls ages 13-15, Ishraq is scaling-up in three of the poorest Upper Egyptian governorates. Working through local and international NGOs, and in collaboration with key government partners including the National Council of Youth, Ishraq has reached 30 new villages and 1,800 girls, ranging in age from 11 to 15 .

\section{Berhane Hewan-"Light of Eve"}

The Population Council, in collaboration with UNFPA and the Ethiopian Ministry of Youth and Sports, created the Berhane Hewan (Light of Eve) program to assist married and unmarried girls by linking them to mentors, social support networks, and services. Berhane Hewan aims to delay marriage and increase school attendance for vulnerable girls in Amhara, Ethiopia-a region where the median age of marriage is 15 for girls (Erulkar and Muthengi 2009). The program promotes functional literacy, life skills, and reproductive health education, along with opportunities for saving money and building livelihood skills. After a successful pilot that provided evidence of having raised the age of marriage among the youngest girls, Berhane Hewan is being scaled-up through the Ethiopian government and now reaches over 10,000 girls throughout Amhara region. A key feature of this project was early involvement of the local governmental units (kebeles) and a focus on keeping the costs within a range that the government could adopt.

\section{Kishori Abhijan, Bangladesh—"Adolescent Girls' Adventure"}

The majority of young girls in Bangladesh find their lives constrained because of early marriage. The Kishori Abhijan program aims to lower school dropout rates, increase girls' independent economic activity, and raise the age at which girls marry. A joint effort of UNICEF, the United Nations Population Fund (UNFPA), the Bangladesh Institute of Development Studies (BIDS), the Bangladesh Rural Advancement Committee (BRAC), and the Centre for Mass Education in Science (CMES), the Kishori Abhijan program combines life-skills and livelihoods training. BRAC and CMES, two large and well known NGOs, implemented the program in 14 rural districts, enrolling 15,000 girls aged 13-22. Based on a successful pilot, evaluated by the Population Council and BIDS, the life-skills component of Kishori Abhijan is being scaled-up through the NGOs to enroll more than 250,000 girls in 58 districts. In an effort to build girls' financial assets, the Council piloted a 20-hour financial education program that has shown promising results. The involvement of the first generation of Kishori Abhijan members as program implementers and mentors in the financial education programs attests to the sustainable and long-term impact of early investments in adolescents.

\section{Siyakha Nentsha_"Building with Young People"}

A Population Council-supported intervention in KwaZulu-Natal, South Africa included boys and girls in a secondary school-based randomized financial, social, and health capabilities program called Siyakha Nentsha, or "Building with Young People" in isiZulu. Girls were the target population because of their vulnerability to HIV and early pregnancy; boys were included to build their knowledge and skills, and to allow girls and boys to work together, interact socially, come to respect one another as colleagues and friends, and thus move beyond objectification of the opposite sex. A panel survey that followed the boys and girls over an 18-month period showed statistically significant program effects. As a result, the Population Council is now collaborating with the KwaZulu-Natal Department of Education and other local partners to scale-up the program in other secondary schools in the province.

\section{Durable insights and key lessons}

To date, most of the successes for girls have been small, fragmented efforts, primarily outside of government plans, systems, and budgets. Achieving larger-scale responses will require financial, technical, and human resources, along with the capability (the skills) and capacity (the ability for volume) to do so. This is particularly the case with scaling-up adolescent girls programs, which need re-enforcement of messages and 
structures, on-going support, and leadership at all levels. Review of the scale-up literature and experience from across the Council's programs have yielded practical lessons that can help guide scaling-up efforts for adolescent girls programs. For example:

- Develop an overarching strategy for scaling-up that delineates roles, processes, and institutional and management responsibilities; a participatory process with relevant stakeholders is essential;

- Conduct an assessment of the comparative advantage of involving different types of institutions;

- Make the most effective use of pilot sites and social innovators as models; learning labs, exchange visits, and study tours are useful mechanisms;

- Maintain and build upon a cadre of female mentors to provide the critical link between the beneficiaries (girls) and the program management; build leadership capacity;

- Determine program elements that are central to success and the outcomes being sought;

- Test the innovation under "real life" conditions;

- Build monitoring and evaluation into the process; and

- Continue to learn, adapt, and re-orient in response to emerging needs and changes in the environment.

Moving forward: Areas for future research and policy advocacy Investing in adolescent girls will have significant long-term benefits for health, especially reproductive health, and socioeconomic development. Interest in girls' role in development is strong and increasing, and comes from UN agencies, governments, bilateral and technical agencies, and foundations. As the momentum builds around scaling-up programs for adolescent girls, research is needed both to guide the scaling-up process and to measure the impact of such efforts. Key issues for consideration include:

- What are realistic expectations for expansion and institutionalization of an adolescent girls innovation?

- What is an appropriate pace and scope for scaling-up the innovation?

-Who will manage the scale-up process?

- How will success be measured (e.g. sustainability, equity, reach)?

- Does adaptation (e.g. adding new elements, deleting, or modifying) of the model produce the desired outcomes observed in the pilot?
- What unexpected results (positive or negative) are observed?

- What is the collective impact?

The Population Council and its partners will continue to experiment with, refine, and document scaling-up processes for adolescent girls programs and seek opportunities to share insights and evidence as they emerge.

\section{References and resources}

Cooley, L. and RI Kohl. 2005. "Scale up - From Vision to Large-scale Change: A Management Framework for Practioners," Washington, DC: Management Systems International.

De Jong, J. 2002. A Question of Scale? Expanding NOG Impact in HIVAIDS. London: ITDG Publishing.

—. 2003. Making an Impact in HIV and AIDS: NGO Experiences of Scaling up. London: ITDG Publishing.

Erulkar, A. and Muthengi, E. 2009. "Evaluation of Berhane Hewan: A program to delay child marriage in rural Ethiopia." International Perspectives on Sexual and Reproductive Health 35(1): 6-14.

ExpandNet. This is a global network of public health professionals and scientists seeking to advance the practice and science of scaling up successful health service innovation. Housed within WHO, its website includes numerous tools and references related to scale-up: www.expandnet.net

Gilson, L. and Schneider, H. 2010. "Managing scaling up: What are the key issues?" Health Policy and Planning 25: 97-98.

Kohl, R. 2011. "An analytical framework for scaling up pilots in public health" in From One to Many: Scaling up Health Programs in Low Income Countries. University Press Limited, pp. 241-254.

Mangham, L. and Hanson, K. 2010. "Scaling up in international health: What are the issues?" Health Policy and Planning 25: 85-96.

Myers, R. 1992. "Going to scale," in Cooperson, W. (ed.), The Twelve Who Survive. London: Routledge, pp.369-396.

Rogers, Everett. 1995. Diffusion of Innovation (4 ${ }^{\text {th }}$ edition). New York: Free Press.

Shiffman, J. 2007. "Generating political priority for public health causes in developing countries: Implications from a study on maternal mortality." Washington, DC: Center for Global Development.

Simmons, Ruth, Peter Fajians, and Laura Ghiron (eds). 2007. Scaling up Health Service Delivery: From Pilot Innovations to Policies and Programmes. Geneva: World Health Organization.

Smith, J. and Colvin, C. 2000. "Getting to scale in young adult reproductive health programs." Focus Tool Series No. 3. FOCUS on Young Adults

\section{Donors}

Population Council

Department for International Development (DFID)

\section{Population Council}

The Population Council changes the way the world thinks about critical health and development issues. We seek to understand the causes and consequences of gender inequality and the disparities in opportunity that arise during adolescence. We provide the evidence for better on-theground programs and policies that ensure successful and productive transitions to adulthood in developing countries. www.popcouncil.org 